\title{
CALCULATION OF MASS BALANCE OF GLACIERS BY REMOTE-SENSING IMAGERY USING SIMILARITY OF ACCUMULATION AND ABLATION ISOLINE PATTERNS*
}

\author{
By A.N. KRENKE and V.M. MENShutin \\ (Institute of Geography, U.S.S.R. Academy of Sciences, Moscow 109017, U.S.S.R.)
}

\begin{abstract}
An investigation of the combined heat, ice, and water balances was carried out in the Marukh glacier basin (west Caucasus) in 1966-67 to 1976-77, according to the International Hydrological Decade programme. Averaged glacier mass balance for these 11 years appears to be $-55 \mathrm{~g} \mathrm{~cm}^{-2}$ year $^{-1}$ according to stake measurements, and $-51 \mathrm{~g} \mathrm{~cm}^{-2}$ year $^{-1}$ according to geodetic measurements. The variability of accumulation is estimated as $C_{\mathrm{v}}=0.15$ and of ablation as $C_{\mathrm{v}}=0.11$. Thus, the variation in accumulation governs the oscillations in glacier balance. The inner nourishment of the glacier was also taken into account. The glacier mass balance is closely related to the relation between the accumulation and ablation areas. The "transient" values of both figures during the whole period of ablation can be used for this relation. The forms of the accumulation and ablation fields are similar from year to year and from one 10 day period to another. The areas of the accumulation and ablation zones are very different from one year to another. On the contrary, the average specific balance for each zone changes very little. One can use these features for the construction of accumulation, ablation, and specific mass-balance maps from satellite imagery. Mean values for the mass-balance terms occur in the vicinity of the equilibrium line. They can be calculated by using the air temperatures. Deviations from the means in different areas of the glacier determine the typical fields of the mass-balance terms.

From 1966-67 until 1976-77, in accordance with the programme of the International Hydrological Decade, studies on heat, ice, and water balance were carried out in the Marukh mountain-glacier basin (the Caucasus; upper reaches of the Marukh River of the Kuban River system). They included snow surveys, measurements of ablation using stakes, gauge run-off measurements at the outlet of the glacier's basin, repeated measurements of thickness, density, and liquid content of the firn layer in the nourishment area, and repeated stereophotogrammetric measurements of the glacier's volume. Equations of the water-ice balance are different for the areas of nourishment and ablation (Krenke, 1973).
\end{abstract}

For the nourishment area:

$$
P_{\mathrm{S}}+P_{\mathrm{e}}+P_{\mathrm{d}}=N_{\text {in }}+R \pm E+N_{\mathrm{s}}
$$

where $P_{\mathrm{S}}$ is solid precipitation, $P_{\mathrm{e}}$ is liquid precipitation, $P_{\mathrm{d}}$ is drift and avalanche horizontal snow transport to the glacier, $E_{\mathrm{c}}$ is condensation, $E_{\mathrm{e}}$ is evaporation, $N_{\mathrm{s}}$ is snow left on the glacier, $N_{\text {in }}$ is inner nourishment due to water refreezing within the ice sequence of the glacier, and $R$ is run-off.

For the ablation area:

$$
P_{\mathrm{S}}+P_{\mathrm{e}}+M \pm P_{\mathrm{d}}+E_{\mathrm{c}}=R \pm E_{\mathrm{e}}
$$

where $M$ is melting of many years' ice.

* See Annals of Glaciology, Vol. 9, 1987, p. 239-40 for an extended abstract.
Accumulation on a glacier $\left(A_{\mathrm{C}}\right)$ is described as

$$
A_{\mathrm{c}}=P_{\mathrm{s}}+P_{\mathrm{d}}+P_{\mathrm{e}} \text {. }
$$

Surface ablation $(A)$ is described as

$$
A=R+N_{\text {in }}+E_{\mathrm{e}} \text {. }
$$

Total ablation $\left(A_{\mathrm{t}}\right)$ is described as

$$
A_{\mathrm{t}}=R+E_{\mathrm{e}}
$$

Mass balance of a glacier $(B)$ is described as

$$
B=A_{\mathrm{c}}-A_{\mathrm{t}} .
$$

Table I demonstrates changes of mass balance in Marukh glacier over 11 years. The amount of ablation corresponds to glacial run-off, since the amount of refreezing or "inner nourishment" was subtracted from the surface melting; in various years the amount of refreezing or "inner nourishment" ranged from 13 to $25 \mathrm{~g} / \mathrm{cm}^{2}$ per unit of area of the glacier. "Inner nourishment" (or internal refreezing) has two components. One is melt water which refreezes in old firn. In determining this by densification we take into account the effects of settling and horizontal expansion (Krenke, 1972). In a pit, this was found to be $27 \mathrm{~g} / \mathrm{cm}^{2}$ in 1967 and $30 \mathrm{~g} / \mathrm{cm}^{2}$ in 1968. It was assumed as $28.5 \mathrm{~g} / \mathrm{cm}^{2}$ for the whole accumulation area for all years. The other component is melt water which refreezes in the remaining new snow. The amount of this water is equal to $7 \%$ of the mass of the remaining snow as it was determined by calorimetric and dielectric methods. The total value for mass balance over 10 years $\left(-55 \mathrm{~g} / \mathrm{cm}^{2}\right)$ agrees well with that determined by the geodetic method $\left(-51 \mathrm{~g} / \mathrm{cm}^{2}\right)$ over the same period.

Values for ablation calculated by a hydrological method (subtraction of liquid precipitation and melting from the non-glacial part of the basin from run-off) differ by only $6 \%$ from calculations based on stake data. Therefore, no corrections were made for data obtained by the stake-pit method.

The components of the mass balance have a small range of variation. The coefficient of variation $\left(C_{\mathrm{v}}\right)$ is 0.15 for accumulation and 0.11 for ablation. However, the netbalance figure varied within a broad range, i.e. from $-121 \mathrm{~g} / \mathrm{cm}^{2}$ in $1974-75$ to $26 \mathrm{~g} / \mathrm{cm}^{2}$ in $1969-70$. The rootmean-square deviation of mass balance was $\pm 46 \mathrm{~g} / \mathrm{cm}^{2}$. This is 0.18 of the mean of the norms of accumulation and ablation.

Because of a comparatively low variability in accumulation and ablation, the calculation of mass balance using meteorological parameters gives higher errors than when the climatological method is used. The climatological method means assuming each annual value equal to the multi-year mean value (Menshutin, 1977). However, remote-sensing methods now open new possibilities based on the relationship between mass balance and its components within 
TABLE I. COMPONENTS OF MASS BALANCE FOR MARUKH GLACIER $\left(\mathrm{g} / \mathrm{cm}^{2}\right)$

\begin{tabular}{|c|c|c|c|c|c|c|c|c|c|c|c|c|}
\hline $\begin{array}{l}\text { Components } \\
\text { of balance }\end{array}$ & $1966-67$ & $1967-68$ & $1968-69$ & $1969-70$ & $1970-71$ & $1971-72$ & $1972-73$ & $1973-74$ & $1974-75$ & $1975-76$ & $1976-77$ & $\begin{array}{l}\text { Average for } \\
\text { many years }\end{array}$ \\
\hline Accumulation & 208 & 249 & 177 & 293 & 203 & 200 & 210 & 242 & 219 & 256 & 228 & 226 \\
\hline Melting & 268 & 289 & 291 & 292 & 309 & 330 & 247 & 302 & 354 & 255 & 326 & 297 \\
\hline $\begin{array}{l}\text { Inner nourishment } \\
\text { (internal refreezing) }\end{array}$ & 15 & 17 & 13 & 25 & 15 & 14 & 16 & 16 & 14 & 17 & 15 & 17 \\
\hline Mass balance & -45 & -23 & -101 & +26 & $\rightarrow 1$ & -116 & -21 & -44 & -121 & +18 & -83 & -54 \\
\hline Balance based on ratio & -54 & -23 & -106 & -8 & -100 & -116 & -25 & -66 & -108 & -14 & -60 & -62 \\
\hline
\end{tabular}

TABLE II. CHANGES IN STRUCTURE OF THE

the accumulation and ablation zones, which are easily identifiable on satellite imagery and air photographs.

Mass balance was compared with the glacial coefficient (K) (Kalesnik, 1939), which is the ratio of the accumulation to the ablation area (Fig. 1). Since most of the observation period included years with a negative mass balance, to obtain higher positive values of mass balance we used the altitude of the snow line and a "transient" glacial coefficient, which was defined not at the end of but during the ablation period.

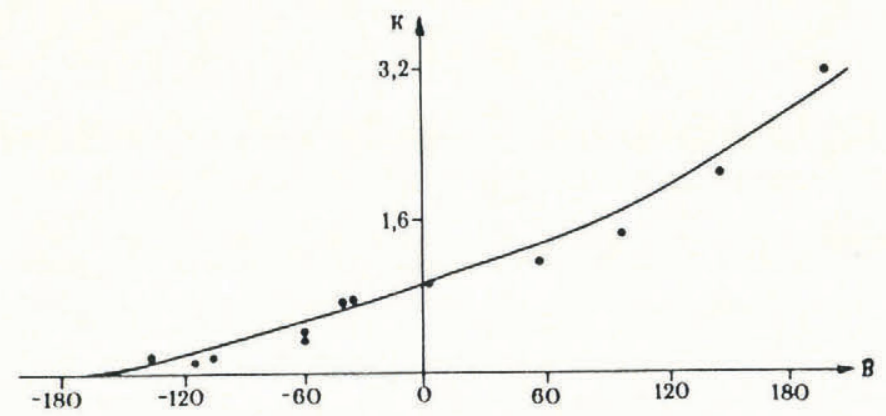

Parts of the basin

$1967-68 \quad 1968-69$

Accumulation area of the glacier $\left(\mathrm{km}^{2}\right) \quad 1.6 \quad 0.7$

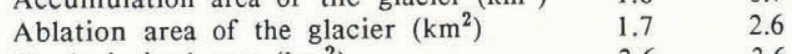

Unglacierized part $\left(\mathrm{km}^{2}\right)$

the basin and ablation remain the same. Higher run-off from the glacier is compensated for in years of low snowfall by a reduction from the unglacierized part. The thickness of snow remaining in the accumulation zone shows little dependence on precipitation; it is only the area which changes and correspondingly the volume of snow remaining. This allows us to determine the remaining layer by measuring the area of the accumulation zone; this is easily done by using the remote-sensing photographs.

The components of the water balance in specific terms for each of the glacier's zones have little dependence on the amount of precipitation; precipitation is most important for the total volume of these components in the accumulation and ablation areas, and accordingly for the components of glacial run-off from the entire basin. The balance features of the glacier in 1968 may be taken as typical. In this year the firn zone accounted for $20-25 \%$ of the run-off, the ablation zone for a little less than $50 \%$, and the unglacierized zone for $33 \%$.

In dry years the contribution of the firn zone in terms of run-off decreased to $10 \%$, whereas the ablation zone increased its contribution to $66 \%$ in proportion to area of the zones. The remaining $24 \%$ is non-glacial run-off. The ratio of each zone's contribution to run-off to its areal percentage is constant. The ratio of glacial to non-glacial run-off increases in dry years; this increase compensates in total run-off for the lower run-off from the unglacierized zone.

Calculation of all the components of the water balance is only possible if data are available for both the area of the various zones and for the air temperature (as recorded by meteorological stations). Summer precipitation can be calculated in this case using data from the nearest meteorological stations. The accuracy of such a calculation is approximately 1.5 times higher than the "climatological" one, which does not take time variation into consideration. In future, it may be possible to calculate all components of glacier balance using an integrated ground remote-sensing system of measurements of area, temperature, precipitation, and albedo of the glacier surface. To solve some of the problems, and glaciological problems in particular, it is essential to know the spatial distribution of the various components of glacier balance within the confines of the glacier. The authors have suggested that such components are similar from year to year, and have examined the possibility of using this fact for calculations. To this end, those years with somewhat different values for average accumulation and ablation were chosen. To make a quantitative comparison, all components were normalized by averaging the parameters for the total period of observation, and then averaging 11 normalized "typical" years (Figs 3 and 4). 
TABLE III. CHANGES IN STRUCTURE OF THE BASIN, WATER BALANCE, AND RUN-OFF DEPENDING ON RAINFALL

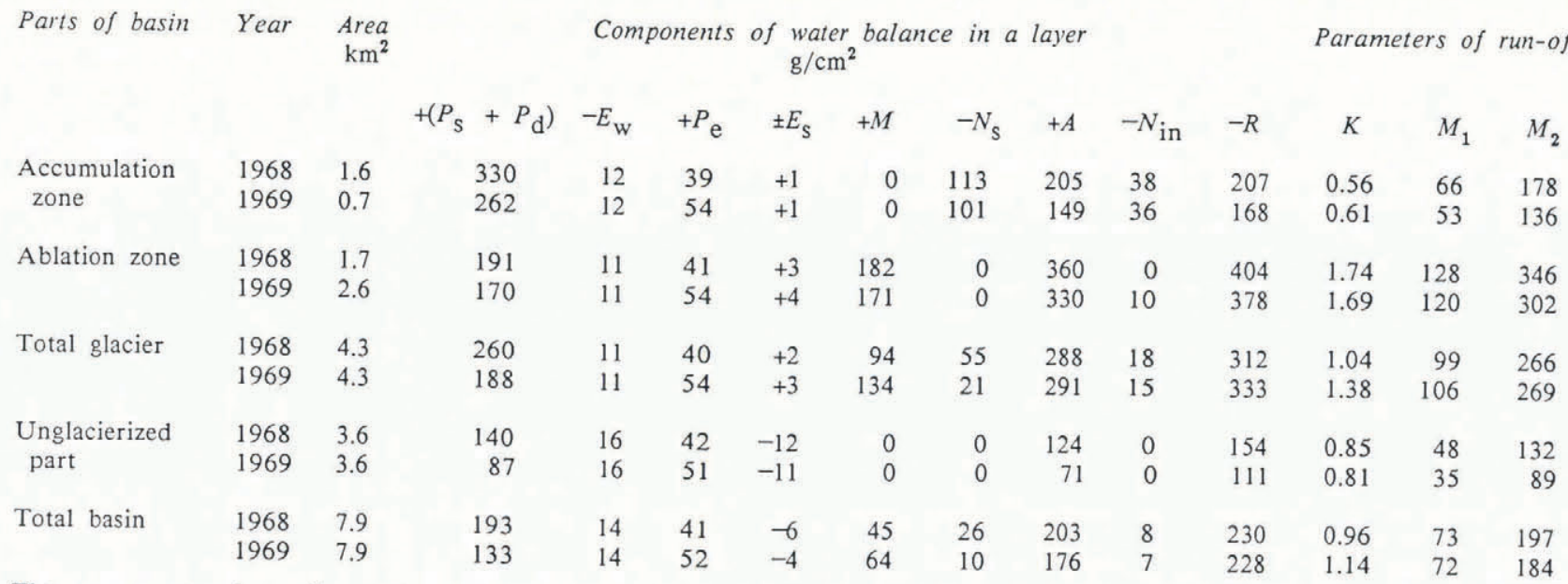

The components depending mainly on precipitation are separated by an unbroken line, and those less dependent by strokes. $E_{\mathrm{W}}$, winter evaporation; $E_{\mathrm{S}}$, summer evaporation; $M_{1}$, run-off module $(1 / \mathrm{s}$ from $\mathrm{km}^{2}$ ) in the basin per year; $M_{2}$, run-off module in the basin calculated for three summer months (June, July, and August); $K$, run-off coefficient equal to $R /\left(P_{\mathrm{w}}+P_{\mathrm{d}}+P_{\mathrm{e}}\right)$.

Since changes in the components of mass balance from year to year consist of changes in the area of each zone and of the water-equivalent layer thickness of these components in each zone, if we know the area of each zone we can considerably reduce the error in calculation of the glacier balance compared to using the climatological method. Zonal variations in the water-equivalent layer thickness for net accumulation and net ablation in the zones of accumulation and ablation are shown in Table IV.

If the root-mean-square variation scattering for an average layer of net accumulation is $\pm 19 \mathrm{~g} / \mathrm{cm}^{2}$, and for a layer of net ablation it is $\pm 33 \mathrm{~g} / \mathrm{cm}^{2}$, the error due to this variation recalculated for the entire area of the glacier is \pm 7 and $\pm 21 \mathrm{~g} / \mathrm{cm}^{2}$, respectively.

The relationship between anomalies in accumulation and ablation is somewhat weak, and therefore the theoretical error in a mass-balance calculation based only on actual areas of the ablation and accumulation zones and of the known average water-equivalent thickness of the balance layer in each of these areas is $\left(7^{2}+21^{2}\right)^{\frac{1}{2}}= \pm 22 \mathrm{~g} / \mathrm{cm}^{2}$, which is twice as accurate as the mass balance calculated on the basis of the climatological norm. The actual error using this method with our data for 11 years (Table I) is $\pm 19 \mathrm{~g} / \mathrm{cm}^{2}$. Since there is no correlation between the specific mean balance of accumulation and ablation with the area of each respective zone, the relationship cannot be used. The error using the mass-balance glacial coefficient relationship is only a little lower $\left( \pm 18 \mathrm{~g} / \mathrm{cm}^{2}\right)$. However, this method allows assessment of individual anomalies in net accumulation and ablation, i.e. of the $N_{\mathrm{S}}$ and $M$ components in Equations (1) and (2). The $N_{\text {in }}$ parameter is determined for Marukh glacier as $\left(28.5+0.07 N_{\mathrm{S}}\right) K /(K+1)$. The value of 28.5 is possibly also applicable to other glaciers with temperate firn zones (Golubev, 1976).

Earlier publications (e.g. Krenke, 1975) have suggested using a method of calculating total accumulation and ablation at the equilibrium line of glaciers based on mean summer air temperature extrapolated to this altitude. Using this relationship, i.e. the sum of melting temperatures extrapolated to the altitude of the transient snow line, it is also possible to calculate the surface ablation of snow and ice $(A)$ for other altitudes. Then the total ablation $\left(A_{\mathrm{t}}\right)$ for the accumulation zone is equal to $A-N_{\text {in }}$ and for the ablation area $A \approx A_{\mathrm{t}}$; since $E$ is small, $A_{\mathrm{t}} \approx R$. Then, accumulation in the zone of nourishment is equal to $A-N_{\mathrm{S}}$, and in the ablation zone $A-M$. Liquid precipitation may be calculated from the curve of precipitation versus altitude using data from meteorological stations. Solid precipitation may be calculated by dividing accumulation by the coefficient of concentration, $\left(x_{\mathrm{s}}+x_{\mathrm{d}}\right) / x_{\mathrm{s}}$, which may be taken as constant from year to year.

Thus, in future it may be possible to calculate, for the glacier being studied, all the components of mass balance by measurements of the accumulation and ablation areas

TABLE IV. CHANGES IN NET ACCUMULATION AND ABLATION IN THE ACCUMULATION AND ABLATION ZONES

$\begin{array}{lccccc}\text { Years } & \begin{array}{c}\text { Area of } \\ \text { accumulation }\end{array} & \begin{array}{c}\text { Net } \\ \text { accumulation }\end{array} & \begin{array}{c}\text { Area of } \\ \text { ablation }\end{array} & \begin{array}{c}\text { Net } \\ \text { ablation }\end{array} & \begin{array}{c}\text { Error of balance calculated according } \\ \text { to "norm of layer" }\end{array} \\ & \mathrm{km}^{2} & \mathrm{~g} / \mathrm{cm}^{2} & \mathrm{~km}^{2} & \mathrm{~g} / \mathrm{cm}^{2} & \mathrm{~g} / \mathrm{cm}^{2} \\ 1966-67 & 1.26 & 85 & 2.04 & 142 & -9 \\ 1967-68 & 1.60 & 113 & 1.70 & 182 & 0 \\ 1968-69 & 0.70 & 101 & 2.60 & 171 & +4 \\ 1969-70 & 1.76 & 78 & 1.54 & 78 & -9 \\ 1970-71 & 0.76 & 126 & 2.54 & 174 & 0 \\ 1971-72 & 0.59 & 81 & 2.71 & 181 & -4 \\ 1972-73 & 1.57 & 121 & 1.73 & 179 & +13 \\ 1973-74 & 1.13 & 85 & 2.17 & 151 & -32 \\ 1974-75 & 0.67 & 99 & 2.63 & 209 & +23 \\ 1975-76 & 1.69 & 145 & 1.61 & 184 & \\ 1976-77 & 1.20 & 120 & 2.10 & 214 & \pm 19 \\ & & & & & \pm 19 \\ \text { Average } & & 105 \pm 19 & 2.10 & 170 \pm 33 & \\ \text { calculated } & 1.20 & 0.18 \pm 7 & & 0.19 \pm 21 & \\ \text { for whole } & & & & & \\ \text { glacier } & & & & & \end{array}$


identified from remote-sensing photographs together with accumulation and ablation calculated from air-temperature data from nearby meteorological stations. Such a calculation is 1.5-2 times more accurate than the "climatological" one, which does not take into account the factor of temporal variability.

For the study area, even if direct observations are not available, it is still possible to make an assessment of the spatial distribution of mass-balance components if it is assumed that the areas of accumulation and ablation are similar from year to year. In order to get a quantitative assessment of the degree of similarity, the fields for each year were normalized by their average parameters, and then the "typical" 11 year normalized fields were calculated (Fig. $2 \mathrm{a}$ and $\mathrm{b})$. The procedure of "normalization" means dividing the individual figures by the averages for the whole glacier.
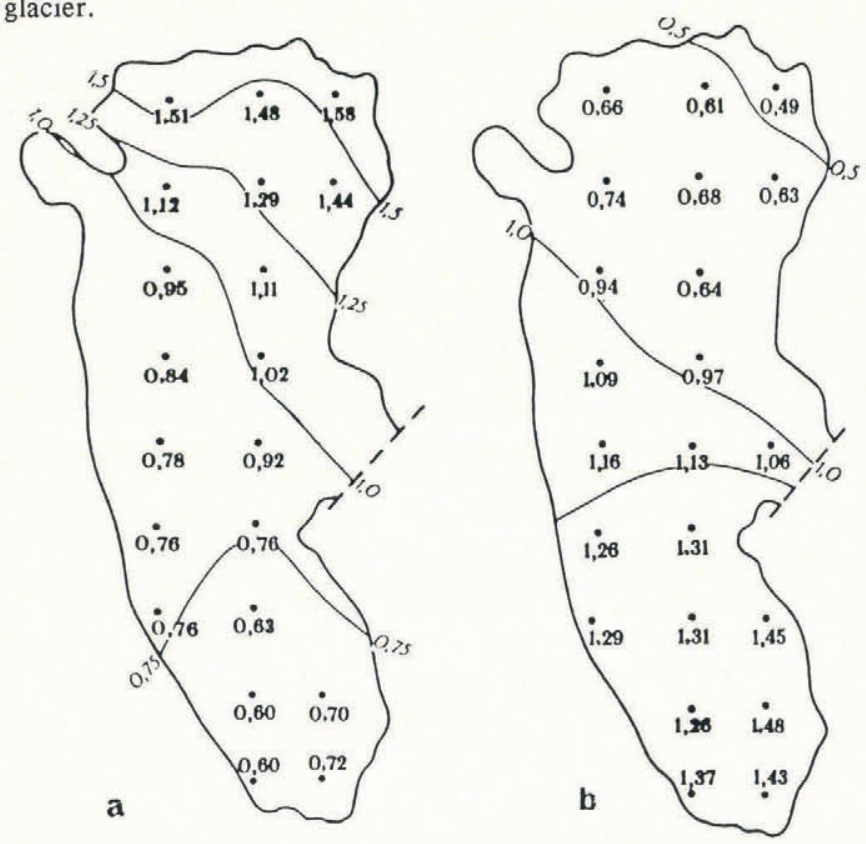

Fig. 2. Fields of mass-balance components normalized for the average area of the glacier: (a) average normalized accumulation over 11 years; (b) average normalized ablation over 11 years.

The deviations of individual fields from the normalized ones are not large. To make a quantitative assessment, coefficients of variation of normalized parameters at each point were calculated (Fig. $3 \mathrm{a}$ and b). For the ablation area the coefficients are everywhere below about 0.20 , and on average they are 0.16 . Therefore, the hypothesis of similarity of ablation area from year to year is confirmed satisfactorily. The variability in the average water-equivalent thickness for ablation is 0.11 ; the variability in area is weakly related to its average; total variability of ablation at a specific point is described by the coefficient of variation, $0.19=\left\{(0.16)^{2}+(0.11)^{2}\right\}^{\frac{1}{2}}$.

The coefficients of variation for normalized parameters of the accumulation field are still below the admissible $20 \%$ error within most of the glacier. However, both the lower part of the glacier which is subject to strong winds from tributary glaciers and that part along the valley have highly variable fields of accumulation with coefficients of variation variable fields of 30 to $40 \%$. Calculations for this part of the field require the introduction of additional parameters which are not readily available (e.g. velocity and direction of winds). However, for most of the glacier it is possible to calculate the area of the accumulation zone. The average coefficient of variation for normalized parameters of accumulation is 0.20 . The variation in the glacier's average total amount of accumulation is 0.15 . Therefore, the coefficient of variation for total accumulation at specific points is $\left\{(0.20)^{2}+(0.15)^{2}\right\}^{\frac{1}{2}}=0.25$.

A variance analysis was made of accumulation and ablation in warm, cold, cloudy, cloudless, dry, and rainy

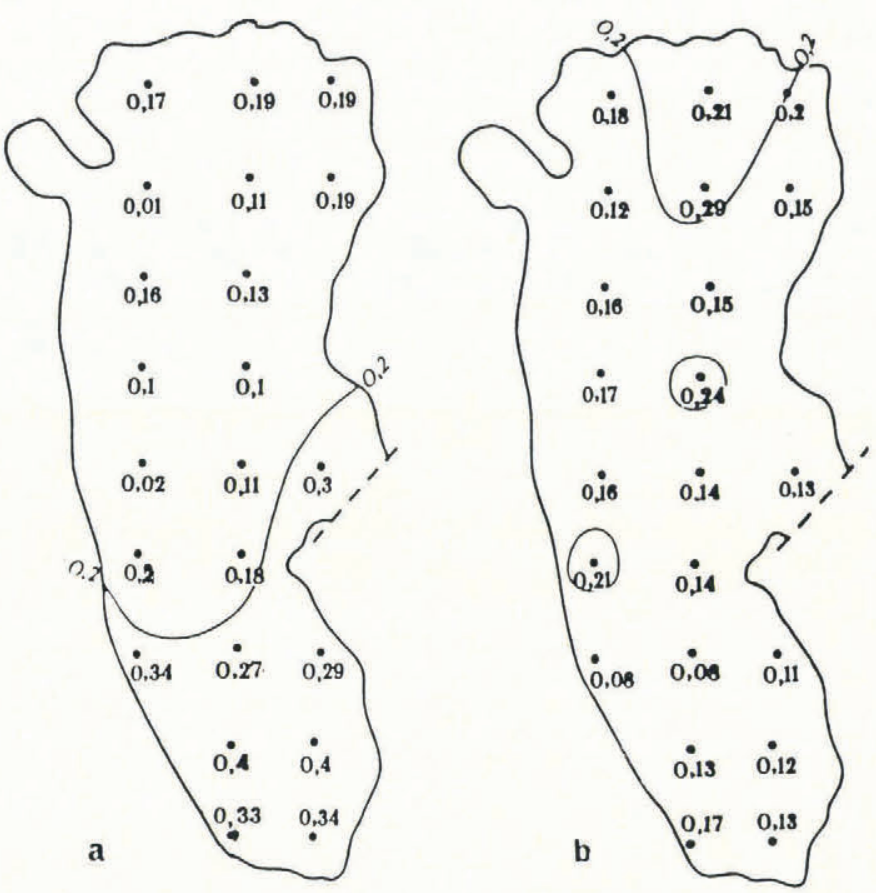

Fig. 3. Fields of coefficients for variation of normalized components of mass balance: (a) coefficients of variation for normalized accumulation; (b) coefficients of variation for normalized ablation.

decades. All fields turned out to be similar (Fig. $4 a$ and b). Isoline patterns correspond mainly to the relief of the land adjacent to the basin and not to that of the glacier itself; there is a similar correspondence of isolines for the accumlation field in the glacial system to the whole relief of the mountainous terrain. This similarity is disturbed in decades with sharply different albedos. However, year-to-year variations in albedo are not very high.

Thus, remote-sensing photographs allow us to assess both the relative and absolute values for the components of mass balance of the glaciers studied previously.
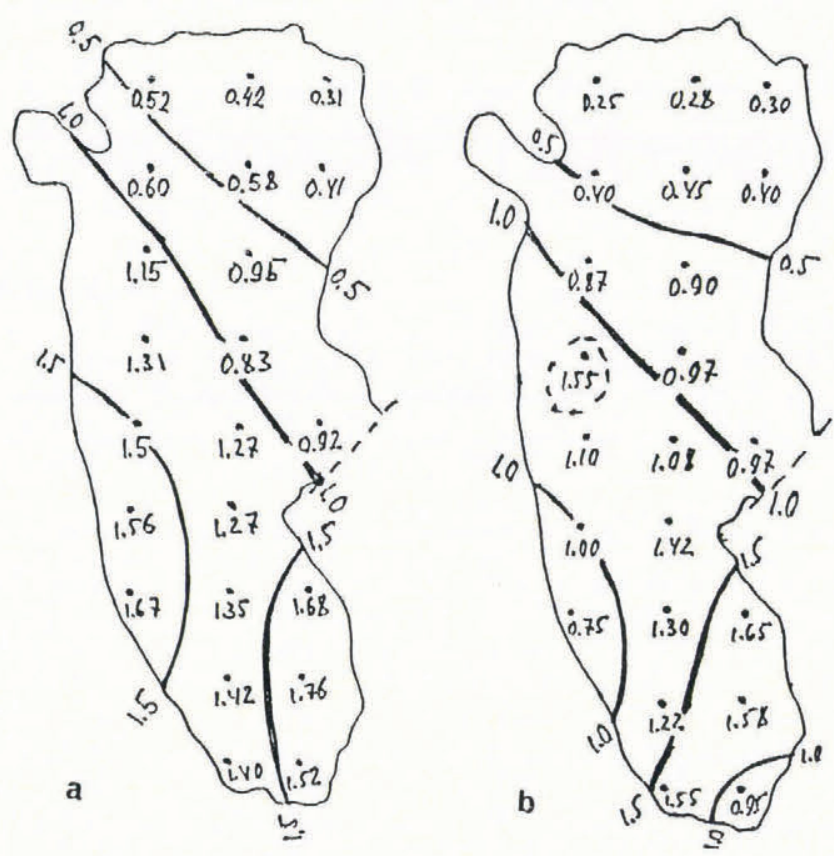

Fig. 4. Parameters of ablation normalized for a glacier's average area using different types of weather: (a) normalized ablation for periods of cloudless weather; (b) normalized ablation for periods of rainy weather. 



Fig. 5. Distribution of normalized mass-balance components for various glaciers. The method of normalizing is given in the text. (a) Distribution of accumulation across various glaciers. ac, normalized accumulation; $b$, normalized width of glaciers. 1, Marukh glacier (Caucasus); 2, Central Tuyuksu glacier (Zaili Alatau, Tianshan); 3, Minor Aktru glacier (Altai). (b) Vertical distribution of ablation: $a$, normalized ablation; $h$, normalized height. 1, Marukh glacier; 2, Jankuat glacier (Caucasus); 3. Abramov glacier (Alai ridge); 4. Central Tuyuksu glacier; 5, Minor Aktru glacier; 6. Glacier No. 31 (Suntar-Hayata ridge, Yakutia).

However, qualitatively the fields of accumulation and ablation show similar ratios for different glaciers; maximum ablation usually occurs close to the snout (the steep terminus itself is shadowed and part of it is buried beneath snow transported by wind); maximum accumulation occurs below back walls of cirques which are in the accumulation zones of glaciers but a little remote from them.

At the glacier margins, ablation is greatest owing to thermal radiation, etc. This similarity may be expected in glaciers of a similar morphological type. We have identified three morphological types, which correspond to the vertical distribution of glaciers. The first type includes glaciers with a maximum area in their lower (according to height) half; the second type has its maximum area near the centre; and, the third type, in the upper part of the glacier. These types correspond to increased complexity in the morphology of the accumulation areas.

To test the similarity between the fields of the components of mass balance for U.S.S.R. glaciers investigated according to the programme of the International Hydrological Decade, normalized values for ablation and accumulation were compared with normalized heights and distances from the glacier's axis.

Normalized heights $(h)$ were found from the expression

$$
h=\frac{H-H_{0}}{H_{\mathrm{b}}-H_{0}}
$$

where $H$ is actual height, $H_{0}$ is height of the glacier's terminus, and $H_{\mathrm{b}}$ is height of the highest point of the glacier. The distance from the glacier's margin was normalized using the same procedure.

Normalized accumulation $(a c)$ was derived from the expression

$$
a c=\frac{a_{\mathrm{c}}-a_{\mathrm{co}}}{a_{\mathrm{cb}}-a_{\mathrm{co}}}
$$

where $a_{\mathrm{c}}$ is actual accumultion, $a_{\mathrm{co}}$ is accumulation at the terminus of the glacier, and $a_{\mathrm{cb}}$ is maximum accumulation on the glacier.

Normalized ablation $(a b)$ was produced according to the expression

$$
a b=\frac{a-a_{0}}{a_{0}-a_{\min }}
$$

where $a$ is actual ablation, $a_{0}$ is ablation at the end of the moraine-free part of the glacier, and $a_{\min }$ is the minimum ablation on that part of the glacier which is free from continuous moraine. Changes in accumulation and ablation across the glacier were normalized in a similar way.

Finally, it transpired that the curves for normalized ablation almost coincide for glaciers of all types (Fig. 5a), and that the curves for normalized accumulation are similar for glaciers of one type (Fig. 5b).

The conclusions show that fundamentally it is possible to calculate accumulation and ablation zones by using remote-sensing photographs of those glaciers; accumulation and ablation parameters had been calculated only up to the equilibrium line from extrapolation of air temperatures and without any observations on these glaciers, by using similarities of accumulation and ablation zones of other glaciers which had already been investigated.

\section{REFERENCES}

Golubev, G.N. 1976. Gidrologiya lednikov [The hydrology of glaciers]. Leningrad, Gidrometeoizdat.

Kalesnik, S.V. 1939. Obshchaya glatsiologiya [General glaciology]. Moscow, Uchpedgiz. 
Krenke, A.N. 1972. Water percolation through the firn body of temperate glacier and formation of glacial run-off according to IHD Marukh representative basin. (In Proceedings of the Wellington Symposium, Dec. 1970. Vol. 2. Wellington, p. 88-101.)

Krenke, A.N. 1973. Run-off formation and water-balance structure of a Caucasian glacier basin. Union Géodésique et Géophysique Internationale. Association Internationale d'Hydrologie Scientifique. Commission de Neiges et Glaces. Symposium on the Hydrology of Glaciers, Cambridge, 7-13 September 1969, p. 251. (Publication No. 95 de l'Association Internationale d'Hydrologie Scientifique.)
Krenke, A.N. 1975. Climatic conditions of present-day glaciation in Soviet Central Asia. [Union Géodésique et Geophysique Internationale. Association Internationale des Sciences Hydrologiques. Commission des Neiges et Glaces.] Symposium. Neiges et Glaces. Actes du Colloque de Moscow, août 1971, p. 30-41. (IAHS-AISH Publication No. 104.)

Menshutin, V.M. 1977. Balans massy Marukh.skogo lednika i izmenchivost' yego sostavlyayushchikh [Mass balance of the Marukh glacier and variability of its components]. Materialy Glyatsiologicheskikh Issledovaniy. Khronika. Obsuzhdeniya, Vyp. 31, p. 38-44.

MS. received in revised form 2 September 1987 